\title{
Functional Outcome of Carpal Tunnel Syndrome After Exercise versus Ultrasound Diathermy
}

\author{
Irma Ruslina Defi', Marina Annette Moeliono', Widjaja Laksmi Kusumaningsih² \\ 1 Department of Physical Medicine and Rehabilitation, Hasan Sadikin General Hospital - Faculty of \\ Medicine Padjajaran University, Bandung. \\ 2 Department of Physical Medicine and Rehabilitation, Ciptomangunkusumo General Hospital - \\ Faculty of Medicine, University of Indonesia, Jakarta
}

\begin{abstract}
Objective: to compare the effectiveness of Tendon and Nerve Gliding Technique (TNGT) exercise with ultrasound diathermy.

Methods: Twenty Carpal Tunnel Syndrome (CTS) hands meet the inclusion criteria and divided into 2 groups: TNGT exercise and Ultrasound group. The subjects' characteristics in the two groups are homogenous.

Results: The statistical analysis results using Friedman test on pain/paresthesia complaint and hand functional status in each group is significant. Using the ANOVA, results of pain/paresthesia complaint between two groups shows a significant difference in the $4^{\text {th }}$ measurement and results of functional status between two groups show a significant difference in the $9^{\text {th }}$ measurement.

Conclusions: Our study emphasized the TNGT exercise combined with splinting will be a good alternative treatment for CTS beside ultrasound diathermy combined with splinting, since TNGT exercise group has the same effectiveness with ultrasound diathermy group in decreasing VAS and has better effectiveness in improvement of FSS.
\end{abstract}

Keywords: CTS, TNGT, Ultrasound Diathermy, VAS, FSS.

\section{INTRODUCTION}

The median nerve at the wrist or carpal tunnel syndrome (CTS) is the most common nerve entrapment of the upper extremity with a prevalence of 5-16\% in the general population 1. Common symptoms of CTS are paresthesia

Received in March 2013 and accepted for published in April 2013.

Correspondence email: Irma Ruslina Devi, irmaruslina@gmail.com or pain, numbness, and tingling in all or a combination of the thumb, index, long and ring finger. The pressure on the median nerve can be released by several treatment options, both surgical and conservative., 3 A non-surgical treatment of CTS is frequently offered to those with mild to moderate symptoms. The current conservative treatments include splints, activity modification, non-steroidal anti-inflammatory drugs, diuretics, pyridoxine, local injection of corticosteroids into carpal tunnel and ultrasound diathermy. ${ }^{2,4-8}$ 
Splinting is the popular method among the conservative treatments of CTS.9-11 Immobilization of the wrist in a neutral position with a splint maximizes carpal tunnel space and minimizes pressure on the median nerve. ${ }^{2,12}$ In addition to splinting, clinical guidelines include home stretching programs. ${ }^{13-15}$ Tendon and nerve gliding technique (TNGT) exercises have been used for the postoperative management of CTS, ${ }^{16}$ while several studies in the literature has used TNGT exercises in conservative management of CTS. The value of these exercises in conservative management of CTS is still unclear. ${ }^{17,18}$ There was limited evidence that TNGT exercise improves outcomes, and few studies have attempted to determine the effective combination of splinting and TNGT exercise for CTS. ${ }^{19,20}$

Ultrasound diathermy has the potential rule to induce biophysical effect inside the nerve tissue. Thermal effect that produces from ultrasound can increase blood flow, local metabolism and tissue regeneration and also reducing edema, inflammation and pain.., 8, 21 There are conflicting results on the efficacy of therapeutic ultrasound in the treatment of CTS, and only a few studies reported the benefit of ultrasound in CTS treatment. ${ }^{2,4,8,22}$

The purpose of this study is to compare the effectiveness of TNGT exercise with ultrasound diathermy, in order to elucidate the appropriate treatment for CTS patients with special circumstances (e.g contraindication with diathermy modality therapy such cancer, sensory disturbance; health service with limited facilities; and time consuming problem).

\section{Material and Methods}

\section{Subject}

A total of 20 patients (all women) from Hasan Sadikin General Hospital, with clinical and electrophysiology evidence of CTS with the

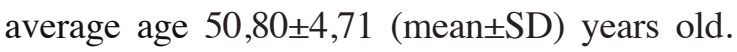
All patients have to sign informed consent. No statistical difference was observed between groups. Patients were divided into 2 groups through randomized assignment method. 10 hands from 10 patients constituted the exercise group; these patients were treated with a splint and TNGT exercise. A custom made neutral volar splint was given to the patients in both groups patients to immobilize the wrist in a neutral position. ${ }^{9}$ The splint has to be used all night and during the day as much as possible for 3 weeks.

The ultrasound diathermy group comprised 10 hands from 10 patients; these patients were treated with splint and ultrasound diathermy (Table 1). Criteria for inclusion in the study were age of 18 years or older, unilateral, idiopathic CTS, and mild to moderate pain and/ or paresthesia in median nerve distribution area lasting more than 3 months. Exclusion criteria were underlying metabolic disorder (diabetes mellitus or thyroid disease), rheumatoid arthritis, pregnancy, history of steroid injection to carpal tunnel, severe thenar atrophy, and history of splint use. Electrophysiological confirmation of the CTS diagnosis was described elsewhere. ${ }^{23,24}$

Table 1. Subjects' Characteristics

\begin{tabular}{|c|c|c|c|}
\hline Variable & $\begin{array}{l}\text { Ultrasound Diathermy } \\
\text { group }(\mathrm{n}=10)\end{array}$ & $\begin{array}{l}\text { TNGT Exercise group } \\
(\mathrm{n}=10)\end{array}$ & $\mathbf{P}$ \\
\hline Age & & & $\mathrm{ns}$ \\
\hline $45-<50$ & 3 & 1 & \\
\hline $50-<55$ & 6 & 6 & \\
\hline$\geq 55$ & 1 & 2 & \\
\hline $\begin{array}{l}\text { Duration of symptoms } \\
\text { (months) }\end{array}$ & $8.80 \pm 4.49$ & $9.50 \pm 3.54$ & $\mathrm{~ns}$ \\
\hline BMI (kg/m2) & $22.57 \pm 1.76$ & $23.73 \pm 1.25$ & ns \\
\hline $\begin{array}{c}\text { VAS } \\
\text { (before intervention) }\end{array}$ & $7.03 \pm 1.01$ & $7.19 \pm 1.00$ & ns \\
\hline $\begin{array}{c}\text { FSS } \\
\text { (before intervention) }\end{array}$ & $3.30 \pm 0.48$ & $3.50 \pm 0.52$ & $\mathrm{~ns}$ \\
\hline
\end{tabular}


This study was approved by the Institutional Review Board of Hasan Sadikin General Hospital. Informed consent was signed by all patients in the study. There were no supplementations given to the patient before and after treatment.

\section{Exercise group}

In addition to TNGT exercises, splint application was required for the exercise group. During tendon gliding exercise, the fingers were placed in five discrete positions. Those were straight, hook, fist, table top, and straight fist. ${ }^{25}$ Median nerve gliding exercises were carried out by putting the hand and wrist in six different positions. ${ }^{16}$ Each position was maintained for $5 \mathrm{sec}$. The exercise was applied as five sessions per day and repeated 10 times at each session. The patient is in a sitting position that varied according to the patient's ability to relax the proximal musculature. The head was placed in the midline and the shoulder in neutral position; the forearm was placed on a table, and the elbow was positioned at 90 degrees of flexion. The patients were instructed to do the exercises as described in the information sheets they received; they were required to keep diaries of their exercises. We checked how often and regularly the patients performed the exercises at home by asking them to bring the diaries and come to hospital 3 times a week for 3 weeks.

\section{Ultrasound diathermy group}

We offered therapeutic ultrasound diathermy which consist of treatment using ultrasound diathermy machine from Enraff Nonius Sonoplus 1.5 watt $/ \mathrm{cm}^{2}$ with frequency $3 \mathrm{MHz}$, and probe diameter $3 \mathrm{~cm} .{ }^{26}$ Splint application was also required for this group. The ultrasound diathermytherapy lasted for 5 minutes per session, 3 times a week, for 3 weeks.

\section{Outcome measurement}

The outcome measurement methods, including Tinel and Phalen test specific for CTS, visual analogue scale (VAS) for pain, and Functional Status Scale (FSS) for hand function, ${ }^{27}$ were carried out for all patients 3 times/week for 3 weeks treatment program. A $100 \mathrm{~mm}$ horizontal VAS was used, with one end labeled no pain and the other unbearable pain. The functional status scale has eight questions. The answers were rated from 1 point (mildest pain or no difficulty with activity) to 5 points (most severe pain or cannot perform activity at all).

\section{Statistical analysis}

The mean and standard deviations were calculated for all subjects in each group for each parameter. The Friedman test was used to compare treatment values within the groups. ANOVA was used to compare the differences of the values between the groups. A p value of less than 0.05 was considered statistically significant. The statistical analysis of the data was done with SPSS (version 16.0 for Windows, SPSS Inc.).

\section{RESULTS}

Before the treatment Tinel and Phalen tests, positive findings were recorded in all 20 hands for both groups. After 3 weeks treatment negative Tinel test results were observed in 1 hand in the exercise group and in 1 hand in the ultrasound diathermy group. After 3 weeks treatment negative Phalen test results were observed in 1 hand in the exercise group and in none of the hands in the ultrasound diathermy group. At the examination performed during 3 weeks of the treatment, there was statistically significant improvement in parameters within both groups using Friedman test. There was a significant improvement in VAS score for pain during the treatment follow up within both groups (Figure 1). Also, there was significant improvement in FSS score for hand function during the treatment follow-up within both groups $(\mathrm{p} \leq 0.01)$ (Figure 2$)$. By using ANOVA, we found the improvement in VAS for exercise group was slightly greater than ultrasound diathermy group, but this difference was not statistically significant (Table 2). The improvement in FSS for exercise group was better than ultrasound diathermy group, and this difference was statistically significant. 
Table 2. Comparison Between Ultrasound Group vs. Tendon Nerve Gliding Exercise Group Exercise Group in Outcome Measurement After 3 Weeks Treatment

\begin{tabular}{cccc}
\hline Variable & Ultrasound & TNGT & P \\
\hline VAS score & $4.62 \pm 1.11$ & $4.78 \pm 0.38$ & 0.681 \\
FSS score & $2.3 \pm 0.23$ & $1.70 \pm 0.23$ & $0.012 *$ \\
\hline
\end{tabular}

Data presented in mean \pm SD; VAS: Visual Analogue Scale; FSS: Functional Status Scale;

* significant different $\mathrm{p}<0.05$

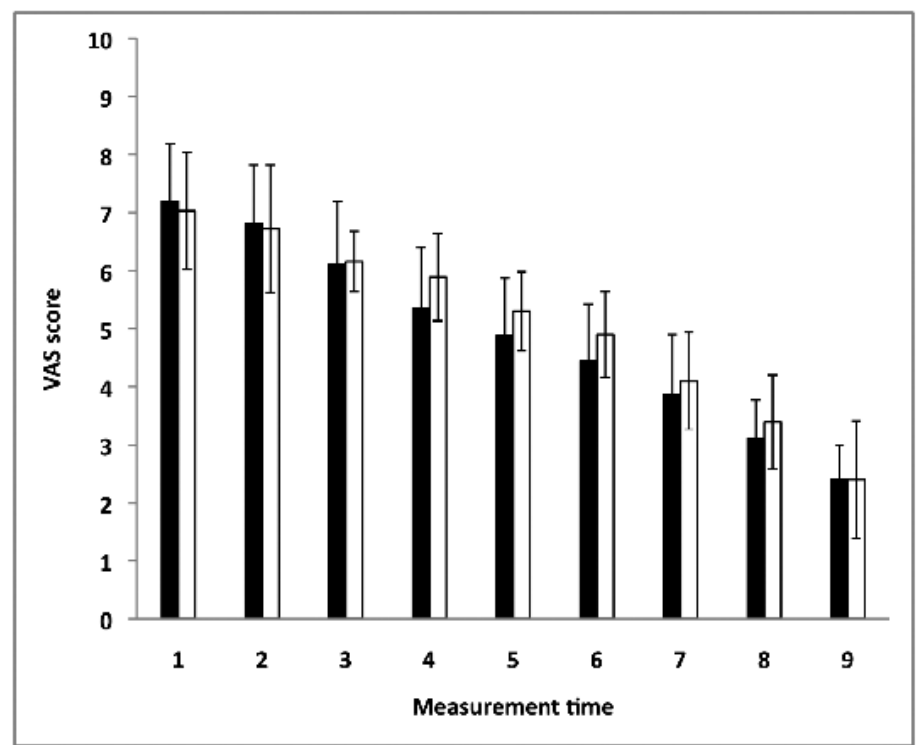

Figure 1. Change of Visual Analogue Scale (VAS) Score for Tendon Nerve Gliding Technique (TNGT) Exercise Group and Ultrasound Group at Each of Measurement Time During 3 Weeks.

$$
\text { (n=10,p<0.01), } \quad \square \text { exercise group } \square \text { ultrasound group }
$$

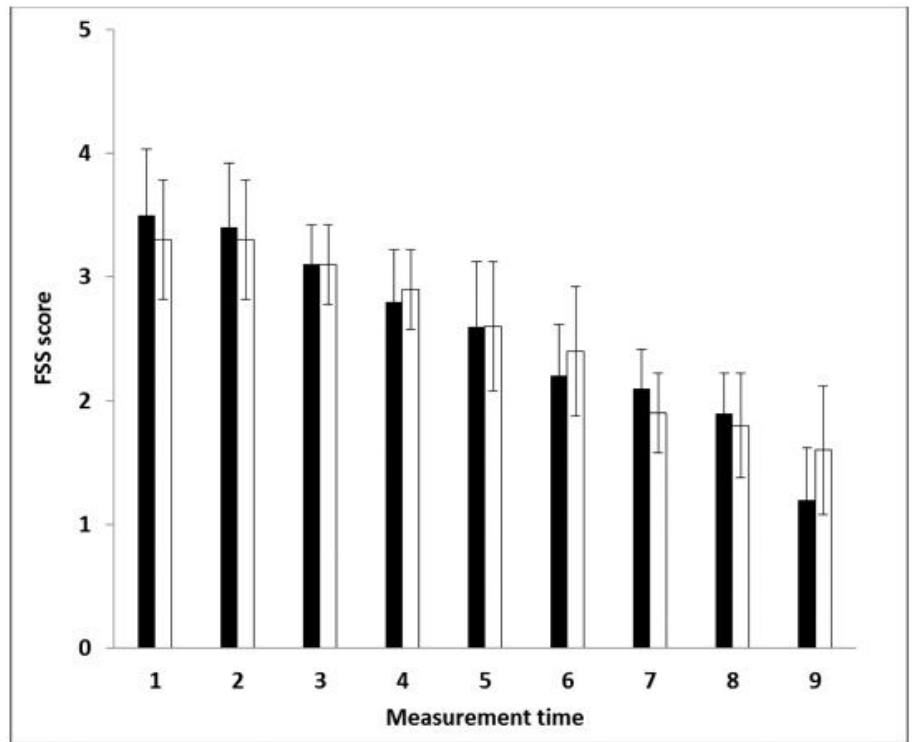

Figure 2. Change of Functional Status Scale (FSS) Score for Tendon Nerve Gliding Technique (TNGT) Exercise group and Ultrasound Group at Each of Measurement Time During 3 Weeks.
$(n=10, p<0.01)$,
exercise group
ultrasound group 


\section{DISCUSSION}

CTS have the potential to substantially limit performance of activities of daily living for some individuals. Manktelow et al reported CTS in Canadian workers could influence a large loss of work productivity and incur a considerable financial cost as a result of workrelated CTS. ${ }^{28}$ The pathophysiology involves a combination of mechanical trauma and ischemic injury to median nerve within the carpal canal. ${ }^{29}$ Currently, several conservative treatments are used to treat CTS. Some authors suggested that patients with CTS could be successfully treated with surgery, although not all patients respond to surgery. ${ }^{2,30,31}$ However, there were also studies reported that the conservative treatment in CTS is ineffective. ${ }^{10,32}$

In this study, negative finding of Tinel test in both groups might due to our sample classification that include only mild to moderate CTS, without thenar atrophy. This reason will make the recovery better in both groups. The ultrasound diathermy group showed significant decreased in VAS and FSS within group. This finding is in agreement with others previous studies. ${ }^{8,26}$ Ultrasound diathermy was shown to increase pain threshold in human subject similar to the level produced by raising tissue temperature by other means. ${ }^{33}$ Hong et al suggested increased local blood flow induced by lower-dose ultrasound diathermy treatment may contribute to nerve regeneration or recovery of nerve conduction in entrapment neuropathy. ${ }^{21}$

Since the significant of VAS improvement in the exercise group was similar to that ultrasound diathermy group, and the FSS was significant different between groups, with better score in exercise group, the role of exercise should be considered. The patients in the exercise group who received TNGT exercise treatment and a splint exhibited improvements in FSS and VAS within group, were consistent with the reported effectiveness of this conventional treatment and justify their clinical value., ${ }^{4,11}$, 17-19, 34 TNGT exercise is a treatment that may reduce symptoms related to CTS by improving the actual excursion of the nerve, decreasing adhesions and reducing symptoms by allowing the nerve to move freely. This technique may also help to oxygenate the nerve, decreasing ischemic pain. ${ }^{35,}{ }^{36}$ Review from Muller et al concluded that a neural mobilization was more effective in relieving pain than no treatment. ${ }^{37}$ According to Rozmaryn et al, nerve and tendon gliding exercises might help to maximize the relative excursion of the median nerve in the $\mathrm{CT}$, as well as the excursion of flexor tendons relative to one another. ${ }^{17}$ Evidence that median nerve excursion can be influenced by neural gliding techniques also demonstrated in a cadaveric study. ${ }^{36}$ Other possible reason for the successful results obtained in our study could be the application of splint.

The rationale for splinting the wrist is supported by finding from several studies., ${ }^{9}, 11$, ${ }^{18,38}$ Splinting may provide sufficient movement between the median nerve and the flexor tendons to prevent adhesions ${ }^{11,39}$ and also immobilization by splinting could maximize the available carpal tunnel space, and minimize the compression. ${ }^{40}$ Splinting also can restrict movement and maintains the wrist and hand in the best anatomic position for minimizing carpal tunnel pressure, ${ }^{41}$ however, controlled of flexion and extension in TNGT exercise, also can reduce the pressure. One study revealed that patients who did not perform TNGT exercises later underwent surgery, whereas surgery was required for only $43.0 \%$ of patients who did perform these exercises. ${ }^{17}$ Akalin et al explained that total of $72 \%$ of the patients in splinting with non-exercise group and $93 \%$ of the patients in splinting with exercise group reported good or excellent results. The difference between these two groups was not statistically significant. ${ }^{18}$ Another study indicated that a group treated with the combination of a splint, ultrasound therapy, and TNGT exercises exhibited more prominent symptomatic improvement than did groups treated with a splint and ultrasound or with a splint and exercise. ${ }^{19}$ Pinar et al reported significant progress was detected in both control and experimental groups during the post treatment phase compared with the initial phase. However, when the 2 groups were compared, the experimental group in which nerve gliding exercises were added to conservative therapy approaches demonstrated more rapid pain reduction; these patients also showed greater 
functional improvement, especially in grip strength. ${ }^{34}$

The other reason why FSS score showed better score in exercise group compare with ultrasound diathermy group, might due to TNGT exercise was done every day by patients at home, and made the patients get to be used to move their hand. When the patients had to perform some activities according to the FSS, the exercise group would be easier to set their hand in motion.

Due to our small sample size, we recognize that the results of this study must be interpreted with caution. In addition, splinting application alone was not taken into consideration. Despite these limitations, the present study emphasized the TNGT exercise combined with splinting will be a good alternative treatment for CTS beside ultrasound diathermy combined with splinting, since TNGT exercise group has the same effectiveness with ultrasound diathermy group in decreasing VAS and has better effectiveness in improvement of FSS. This suggests that the TNGT exercise could be used for CTS patients with specific circumstance; patients in living with limited health facilities, patients with diathermy's contraindication and patient with low compliance due to difficulty to access health service and time consuming treatment.

\section{CONCLUSIONS}

This study found that TNGT exercise in combination with splinting could be a better CTS management alternative to beside ultrasound diathermy in combination with splinting. Both groups were able to decrease VAS, while TNGT group showed to be effective in resulting FSS improvement. Thus, TNGT exercise could be used for CTS patients with specific circumstance; patients with limited health facilities, diathermy's contraindication and low compliance due to limitation to access health service and time consuming treatment.

Acknowledgements The author would like to express their gratitude to Dr. Farida Arisanti SpRM and Dr. Evi Yulianti SpRM for helping in the data collection of this study. Also to Dr Marina Moeliono SpRM, for her support, advice and fruitful discussion for the data analysis.

\section{REFERENCES}

1. Tanaka S, Wild DK, Seligman PJ, Behrens V, Cameron L, Putz-Anderson V. The US prevalence of self-reported carpal tunnel syndrome: 1988 National Health Interview Survey data. Am J Public Health. 1994 Nov;84(11):1846-8.

2. Gerritsen AA, de Krom MC, Struijs MA, Scholten RJ, de Vet HC, Bouter LM. Conservative treatment options for carpal tunnel syndrome: a systematic review of randomised controlled trials. J Neurol. 2002 Mar;249(3):272-80.

3. Shum C, Parisien M, Strauch RJ, Rosenwasser MP. The role of flexor tenosynovectomy in the operative treatment of carpal tunnel syndrome. J Bone Joint Surg Am. 2002 Feb;84-A(2):221-5.

4. Bakhtiary AH, Rashidy-Pour A. Ultrasound and laser therapy in the treatment of carpal tunnel syndrome. Aust $\mathrm{J}$ Physiother. 2004;50(3):147-51.

5. Marshall S, Tardif G, Ashworth N. Local corticosteroid injection for carpal tunnel syndrome. Cochrane Database Syst Rev. 2007(2):CD001554.

6. Werner RA, Franzblau A, Gell N. Randomized controlled trial of nocturnal splinting for active workers with symptoms of carpal tunnel syndrome. Arch Phys Med Rehabil. 2005 Jan;86(1):1-7.

7. Giannini F, Passero S, Cioni R, Paradiso C, Battistini N, Giordano N, et al. Electrophysiologic evaluation of local steroid injection in carpal tunnel syndrome. Arch Phys Med Rehabil. 1991 Sep;72(10):738-42.

8. Ebenbichler GR, Resch KL, Nicolakis $\mathrm{P}$, Wiesinger GF, Uhl F, Ghanem AH, et al. Ultrasound treatment for treating the carpal tunnel syndrome: randomised "sham" controlled trial. BMJ. 1998 Mar 7;316(7133):731-5.

9. Burke DT, Burke MM, Stewart GW, Cambre A. Splinting for carpal tunnel 
syndrome: in search of the optimal angle. Arch Phys Med Rehabil. 1994 Nov;75(11):1241-4.

10. Weiss AP, Sachar K, Gendreau M. Conservative management of carpal tunnel syndrome: a reexamination of steroid injection and splinting. J Hand Surg Am. 1994 May;19(3):410-5.

11. Brininger TL, Rogers JC, Holm MB, Baker NA, Li ZM, Goitz RJ. Efficacy of a fabricated customized splint and tendon and nerve gliding exercises for the treatment of carpal tunnel syndrome: a randomized controlled trial. Arch Phys Med Rehabil. 2007 Nov;88(11):1429-35.

12. Gerritsen AA, de Vet HC, Scholten RJ, Bertelsmann FW, de Krom MC, Bouter LM. Splinting vs surgery in the treatment of carpal tunnel syndrome: a randomized controlled trial. JAMA. 2002 Sep 11;288(10):1245-51.

13. Huisstede BM, Hoogvliet P, Randsdorp MS, Glerum S, van Middelkoop M, Koes BW. Carpal tunnel syndrome. Part I: effectiveness of nonsurgical treatments-a systematic review. Arch Phys Med Rehabil. Jul;91(7):981-1004.

14. Huisstede BM, Randsdorp MS, Coert JH, Glerum S, van Middelkoop M, Koes BW. Carpal tunnel syndrome. Part II: effectiveness of surgical treatments--a systematic review. Arch Phys Med Rehabil. Jul;91(7):1005-24.

15. O'Connor D MS, Massy-Westropp N. Non-surgical treatment (other than steroid injection) for carpal tunnel syndrome. Cochrane Database Syst Rev 2009; (1):CD003219. 2009;1.

16. Totten PA, Hunter JM. Therapeutic techniques to enhance nerve gliding in thoracic outlet syndrome and carpal tunnel syndrome. Hand Clin. 1991 Aug;7(3):50520.

17. Rozmaryn LM, Dovelle S, Rothman ER, Gorman K, Olvey KM, Bartko JJ. Nerve and tendon gliding exercises and the conservative management of carpal tunnel syndrome. J Hand Ther. 1998 JulSep;11(3):171-9.

18. Akalin E, El O, Peker O, Senocak O, Tamci
S, Gulbahar S, et al. Treatment of carpal tunnel syndrome with nerve and tendon gliding exercises. Am J Phys Med Rehabil. 2002 Feb;81(2):108-13.

19. Baysal O, Altay Z, Ozcan C, Ertem K, Yologlu S, Kayhan A. Comparison of three conservative treatment protocols in carpal tunnel syndrome. Int J Clin Pract. 2006 Jul;60(7):820-8.

20. Luchetti R, Schoenhuber R, Alfarano M, Deluca S, De Cicco G, Landi A. Serial overnight recordings of intracarpal canal pressure in carpal tunnel syndrome patients with and without wrist splinting. J Hand Surg Br. 1994 Feb;19(1):35-7.

21. Hong CZ, Liu HH, Yu J. Ultrasound thermotherapy effect on the recovery of nerve conduction in experimental compression neuropathy. Arch Phys Med Rehabil. 1988 Jun;69(6):410-4.

22. Burke FD, Ellis J, McKenna H, Bradley MJ. Primary care management of carpal tunnel syndrome. Postgrad Med J. 2003 Aug;79(934):433-7.

23. Charles N, Vial C, Chauplannaz G, Bady B. Clinical validation of antidromic stimulation of the ring finger in early electrodiagnosis of mild carpal tunnel syndrome. Electroencephalogr Clin Neurophysiol. 1990 Aug;76(2):142-7.

24. Gerritsen AA, Scholten RJ, Assendelft WJ, Kuiper H, de Vet HC, Bouter LM. Splinting or surgery for carpal tunnel syndrome? Design of a randomized controlled trial [ISRCTN18853827]. BMC Neurol. 2001 Dec 18;1:8.

25. Wehbe MA, Hunter JM. Flexor tendon gliding in the hand. Part II. Differential gliding. J Hand Surg Am. 1985 Jul;10(4):575-9.

26. Oztas O, Turan B, Bora I, Karakaya MK. Ultrasound therapy effect in carpal tunnel syndrome. Arch Phys Med Rehabil. 1998 Dec;79(12):1540-4.

27. Levine DW, Simmons BP, Koris MJ, Daltroy LH, Hohl GG, Fossel AH, et al. A self-administered questionnaire for the assessment of severity of symptoms and functional status in carpal tunnel syndrome. J Bone Joint Surg Am. 1993 
Nov;75(11):1585-92.

28. Manktelow RT, Binhammer P, Tomat LR, Bril V, Szalai JP. Carpal tunnel syndrome: cross-sectional and outcome study in Ontario workers. J Hand Surg Am. 2004 Mar;29(2):307-17.

29. Werner RA, Andary M. Carpal tunnel syndrome: pathophysiology and clinical neurophysiology. Clin Neurophysiol. 2002 Sep;113(9):1373-81.

30. Cotton P. Symptoms may return after carpal tunnel surgery. JAMA. 1991 Apr 17;265(15):1922, 5.

31. Hwang PY, Ho CL. Minimally invasive carpal tunnel decompression using the KnifeLight. Neurosurgery. 2007 Feb;60(2 Suppl 1):ONS162-8; discussion ONS8-9.

32. Katz JN, Keller RB, Simmons BP, Rogers WD, Bessette L, Fossel AH, et al. Maine Carpal Tunnel Study: outcomes of operative and nonoperative therapy for carpal tunnel syndrome in a community-based cohort. J Hand Surg Am. 1998 Jul;23(4):697-710.

33. Lehmann JF, Brunner GD, Stow RW. Pain threshold measurements after therapeutic application of ultrasound, microwaves and infrared. Arch Phys Med Rehabil. 1958 Sep;39(9):560-5.

34. Pinar L, Enhos A, Ada S, Gungor N. Can we use nerve gliding exercises in women with carpal tunnel syndrome? Adv Ther. 2005 Sep-Oct;22(5):467-75.

35. Medina McKeon JM, Yancosek KE.
Neural gliding techniques for the treatment of carpal tunnel syndrome: a systematic review. J Sport Rehabil. 2008 Aug;17(3):324-41.

36. Ettema AM, Zhao C, Amadio PC, O'Byrne $\mathrm{MM}, \mathrm{An} \mathrm{KN}$. Gliding characteristics of flexor tendon and tenosynovium in carpal tunnel syndrome: a pilot study. Clin Anat. 2007 Apr;20(3):292-9.

37. Muller M, Tsui D, Schnurr R, BiddulphDeisroth L, Hard J, MacDermid JC. Effectiveness of hand therapy interventions in primary management of carpal tunnel syndrome: a systematic review. J Hand Ther. 2004 Apr-Jun;17(2):210-28.

38. Weiss ND, Gordon L, Bloom T, So Y, RempelDM.Position of the wristassociated with the lowest carpal-tunnel pressure: implications for splint design. J Bone Joint Surg Am. 1995 Nov;77(11):1695-9.

39. Szabo RM, Bay BK, Sharkey NA, Gaut C. Median nerve displacement through the carpal canal. J Hand Surg Am. 1994 Nov;19(6):901-6.

40. Kruger VL, Kraft GH, Deitz JC, Ameis A, Polissar L. Carpal tunnel syndrome: objective measures and splint use. Arch Phys Med Rehabil. 1991 Jun;72(7):51720.

41. Seradge H, Jia YC, Owens W. In vivo measurement of carpal tunnel pressure in the functioning hand. J Hand Surg Am. 1995 Sep;20(5):855-9. 